run charts have been produced and local centres are considering how to best achieve this improvement.

The next stages involve identifying and implementing further improvements both locally and regionally. We are hoping to utilise a nurse or allied healthcare professional via the regional paediatric network to facilitate this. For all interventions, the PDSA cycles with continuous monitoring of outcomes will be used to track effects. Where local changes lead to improvement in outcomes, we will use the regional nature of the project to enable other centres to learn and benefit from this learning.

\section{G408(P) THE PRODUCTION OF A DIABETES INFORMATION FILM, BY YOUNG PEOPLE WHO HAVE DIABETES, AS A MEANS OF EDUCATING OTHERS}

${ }^{1}$ VE Dublon, ${ }^{2} \mathrm{~S}$ Green, ${ }^{1} \mathrm{M}$ Benitez-Castillo, ${ }^{3} \mathrm{~T}$ Edwards, ${ }^{4} \mathrm{~A}$ Leiva. ${ }^{1}$ Child Health, Royal Free Hospital, London, UK; ${ }^{2}$ Hospital School, Royal Free Hospital, London, UK; ${ }^{3}$ Child Health, Royal Free Hospital, London, UK; ${ }^{4}$ E17 Puppet Projet, London, UK

\subsection{6/archdischild-2018-rcpch.397}

Method After establishing a group of regular attendees to our Diabetes Education Days we wanted to make these more patient centred. We obtained a grant from the Diabetes Research and Wellness Foundation. Through the medium of puppet making and learning film skills the young people felt empowered producing their own educational film. Throughout the process, of four sessions spread over four weeks, the young people were supported by a multidisciplinary team consisting of consultant paediatrician, a specialist diabetes nurse, the deputy head of the Hospital school, a dietician, a team of professional puppet makers, and a film making expert. In addition to filming the actual process, the participants wrote and filmed their individual screenplays. There was opportunity to explore individual experiences and knowledge of diabetes in a fun, non-judgemental setting. Full consent was given by all attendees regarding the final distribution and use of the film.

Results The first of four sessions was a resounding success. Young people were desperate to attend the following sessions, altering schedules to ensure they could make them. During the process it became very clear they would like the film to be used as an educational tool. The response to the first viewing has given great verbal feedback and we are now in the process of collating formal qualitative data from the following groups: Children at the Royal Free Hospital School without diabetes, those with a new diagnosis and those who already have diabetes, which will be ready to be shared at the conference.

Conclusion Young people with diabetes embraced these sessions with huge enthusiasm. Having previously not known each other they quickly formed friendships and all actively took part, encouraging each other. They expressed and explored their knowledge in a relaxed environment, very different from clinic; given a rare and valuable opportunity to fully voice their opinions. At the same time, they loved the idea that the film productions they contributed to may go on to help other people.

For the professionals it was an incredibly inspiring experience and the film really does show diabetes through the eyes of the young people themselves.
G409(P) SAFETY CLIMATE \& CULTURE A SURVEY OF PAEDIATRIC STAFF IN DISTRICT GENERAL HOSPITAL

S Kamath, A Khan. Paediatrics, Daisy Hill Hospital, Southern Health and Social Care Trust, Newry, UK

\subsection{6/archdischild-2018-rcpch.398}

Background Organisations working towards a culture of safety need a reliable measure to monitor the success of their initiatives. Using Safety survey tool, an organisation can gain information about the perceptions of front-line clinical staff.

Aim To gain information about safety in the clinical area and management's commitment to safety.The survey also provides information about how perceptions vary across Multi-disciplinary teams (MDT).

Method QI Working group carried out Literature search for safety climate and culture.RCPCH -Safety survey was selected. Survey was pretested with a small group to ensure easy understanding and relevance.Survey was completed by MDT, medical, nursing, administrative and health care assistants in the Paediatric department.

Results 38 completed surveys received.Survey looked at Patient safety, Leadership, Staffing and communication.About $72 \%$ agreed that concerns were listened to by senior management. $76 \%$ agreeing that systems were in place to address concerns. $74 \%$ agreed that there was a medical and nursing leadership drive towards a safety centred organisation.Discussing errors at work was deemed easy. $72 \%$ felt that medical errors were handled appropriately. $65 \%$ received appropriate feedback about performance.

Conclusion This survey provided us in-depth information of safety culture within the department. It provided insight regarding various MDT's safety perception. We plan to address issues about error discussion. The Safety Awareness For Everyone i.e. SAFE initiative aims to reduce harm and improve safety.

\section{REFERENCE}

1. Safety Climate Survey. http://primaris.org/sites/default/files/resources/Patient\% 20Safety/safety\%20climate\%20survey.pdf

\section{G410(P) SHOULD ACCIDENTAL ADMINISTRATION OF RESIDUAL ANAESTHETIC AGENTS IN INTRAVENOUS LINES IN CHILDREN BE CLASSED A 'NEVER EVENT'?}

${ }^{1,2} \mathrm{C}$ Kanaris. 'North West and North Wales Paediatric Transport Service, Warrington, UK; ${ }^{2}$ The Centre for Social Ethics and Policy, The University of Manchester, Manchester, UK

\subsection{6/archdischild-2018-rcpch.399}

General surgical and paediatric teams are increasingly required to share the responsibility of the postoperative care of children undergoing routine surgical procedures, they are therefore the first to be called should a child become unwell in the immediate postoperative period. With this in mind it is imperative to raise awareness of potentially catastrophic consequences following the administration of residual neuromuscular blocking agents that may linger in the intravenous line after the patients have returned from theatre.

Incident reports of patients accidentally receiving residual neuromuscular blocking drug in the intravenous line following an operation may be rare but it is a clinical problem with potentially grave sequelae and one not currently classed as a 'never event' 